
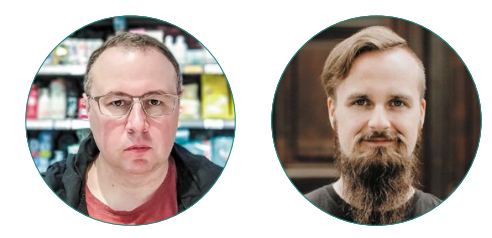

Р. Н. Абрамов, А. В. Быков

\title{
МИР ПРОФЕССИЙ В КОНТЕКСТЕ ТРУДА И ЗАНЯТОСТИ: ПАНДЕМИЧЕСКОЕ И ЦИФРОВОЕ ВЕРТИГО
}

\section{Правильная ссылка на статью:}

Абрамов Р.Н., Быков А.В. Мир профессий в контексте труда и занятости: пандемическое и цифровое вертиго // Мониторинг общественного мнения: экономические и социальные перемены. 2021. № 3. С. 4-20. https://doi.org/10.14515/monitoring.2021.3.2001.

\section{For citation:}

Abramov R. N., Bykov A. V. (2021) The World of Professions in the Context of Work and Employment: Pandemic and Digital Vertigo. Monitoring of Public Opinion: Economic and Social Changes. No. 3. P. 4-20. https://doi.org/10.14515/monitoring.2021.3.2001. (In Russ.) 
МИР ПРОФЕССИЙ В КОНТЕКСТЕ ТРУДА И ЗАНЯТОСТИ: ПАНДЕМИЧЕСКОЕ И ЦИФРОВОЕ ВЕРТИГО

АБРАМОВ Роман Николаевич - доктор социологических наук, профессор кафедры анализа социальных институтов Департамента социологии, ведущий научный сотрудник Международной лаборатории исследований социальной интеграции, Национальный исследовательский университет "Высшая школа экономики", Москва, Россия; ведущий научный сотрудник, Институт социологии ФНИСЦ РАН, Москва, Россия

E-MAIL: rabramov@hse.ru

https://orcid.org/0000-0002-4967-1169

БыКОВ Андрей Вячеславович - кандидат социологических наук, доцент кафедры анализа социальных институтов Департамента социологии, Национальный исследовательский университет "Высшая школа экономики", Москва, Россия; научный сотрудник, Институт социологии ФНИСЦ РАН, Москва, Россия

E-MAIL:a.bykov@hse.ru

https://orcid.org/0000-0001-8391-8674

Аннотация. Данная статья является вступительной к специальному номеру журнала, посвященному трансформации профессий и занятий в современных условиях. Основная цель статьи анализ социального, технологического и экономического контекста, в котором сегодня находятся российские профессии и занятия, а также характеристика новейших исследований в этой области, которые проводятся в России и за рубежом. Сначала обозначаются ключевые вызовы профессионализму, включая волатильность пандемии коронавируса и ее влияние на профес-
THE WORLD OF PROFESSIONS IN THE CONTEXT OF WORK AND EMPLOYMENT: PANDEMIC AND DIGITAL VERTIGO

Roman N. ABRAMOV ${ }^{1,2}-$ Dr. Sci. (Soc.), Professor, Department for Social Institutions Analysis, School of Sociology; Leading Research Fellow, International Laboratory for Social Integration Research; Leading Research Fellow

E-MAIL: rabramov@hse.ru

https://orcid.org/0000-0002-4967-1169

Andrey V. BYKOV ${ }^{1,2}$ - Cand. Sci. (Soc.), Associate Professor, Department for Social Institutions Analysis, School of Sociology; Research Fellow

E-MAIL:a.bykov@hse.ru

https://orcid.org/0000-0001-8391-8674

\footnotetext{
${ }^{1}$ HSE University, Moscow, Russia

2 Institute of Sociology of FCTAS RAS, Moscow, Russia
}

Abstract. This article is an Introduction to the special issue of the journal, which is focused on the recent transformations of professions and occupations. The main purpose of the article is to analyze the contemporary social, technological, and economic context, in which Russian professions and occupations are, and to review the latest research in this field conducted both in Russia and abroad. First, we identify key modern challenges to professionalism, including the volatility of the COVID-19 pandemic and its impact on professional work, the development of digital labor platforms, and 
сиональный труд, развитие цифровых платформ труда и занятости, реакции государства и менеджмента на новые вызовы применительно к контролю за сферой труда. Далее дается обзор новейших зарубежных работ, посвященных профессиям и профессионализму. Констатируется, что социология профессий как самостоятельная дисциплинарная область находится в кризисе, поскольку сложившиеся теоретические модели профессионализма проверяются на прочность стремительно меняющейся структурой профессиональной занятости, методами контроля и управления профессиональным трудом и трансформациями содержания этого труда. В частности, рассматриваются концепции "связующего профессионализма" и "клиентского профессионализма" и показывается, как профессии сегодня формируют свою институциональную идентичность в организационном и менеджериальном контекстах. Затем предлагается краткий аналитический очерк о статьях, опубликованных в данном номере журнала. В заключительной части обозначаются перспективы исследований занятий и профессий. Говорится о растущей роли цифровых технологий организации труда, трансформации структуры занятости в постпандемийном мире, недоизученности многих трудовых занятий в России в социологической перспективе.

Ключевые слова: профессионализм, занятость, труд, цифровизация, платформенная занятость, пандемия, этика how the state and management react to all of these. Next, we provide an overview of some latest research on professions and professionalism. We suggest that the sociology of professions, as an independent disciplinary field, is currently in crisis. This is because the established theoretical models of professionalism are being questioned by the rapidly changing structure of professional employment, methods of control and management of professional work, as well as transformations of the content of this work. In particular, we consider the concepts of "connecting professionalism" and "client professionalism" and show how contemporary professions form their institutional identity in organizational and managerial contexts. Then, in this context, we provide a brief review of the articles that are published in this special issue. Finally, we discuss some possible directions for future research on professions and professionalism, with a special focus on the digitalization process and the pandemic crisis.

Keywords: professionalism, employment, labor, digitalization, platform work, pandemic, ethics 


\section{Введение}

Замысел этого специального номера "Мониторинга", посвященного теме профессий и занятий в современном контексте, возник совсем в других условияхкак теперь принято говорить, в допандемической реальности. Нам казалось, что ситуация в мире профессий, а следовательно, и повестка изучения профессионализма активно обновлялись под влиянием целого ряда обстоятельств - от более глубокого проникновения цифровых технологий в сферу труда и в нашу повседневность до возникновения профессионализированных практик взаимопомощи и новых форм эмоционального труда.

Пандемия COVID-19 смоделировала условия глобального социального, политического и экономического эксперимента, который затронул личную и трудовую жизнь, баланс работы и отдыха, мировоззрение и повседневные практики каждого жителя планеты. Занятость и профессиональный труд стали сферами, пережившими глубокие потрясения, в процессе которых мы еще находимся и последствия которых пока до конца не ясны. Научная и практическая медицина, биология и генетика, фармацевтическая отрасль оказались на передовой войны с эпидемией, а общество по-новому взглянуло на труд медицинских работников, включая дилеммы профессиональной морали и сущностную роль медицинской профессии для биологического воспроизводства общества, о которых писал еще Г. Спенсер [Dingwall, King, 1995]. На этом фоне не только у социологов профессий и занятий, но и у многих правительственных экспертов по всему миру возникли сомнения в магистральном пути реформирования занятий социальной сферы, опирающемся на принципы New Public Management, квантифицированной результативности, коммерческой эффективности и lean production. Это самый очевидный пример изменений во взглядах на профессиональный труд, хотя большому испытанию подверглись многие другие занятия: форс-мажорный переход на дистанционное онлайн-обучение в школах и вузах заставило задуматься о социальной роли педагога в современном мире [Rogozin, Vyugovskaya, 2021; Tomczyk, 2021], а фактический крах мировой туристической индустрии ставит вопрос о том, не были ли слишком поспешными констатации и прогнозы относительно окончательной и бесповоротной победы экономики впечатлений и третичного сектора, где занятия сферы торговли, рекреационных услуг и развлечений выходят на первый план.

Так называемая реальная экономика вместе с заботой о здоровье и борьбой с болезнями снова зримо заявила о себе: становится понятно, что рано отправлять на "задний двор" цивилизации многие виды деятельности эпохи индустриализма и модерна. С другой стороны, пандемия стимулировала развитие ряда отраслей городской экономики, спровоцировав соответствующие изменения в социально-профессиональной структуре. В крупных городах России существенно вырос сегмент платформенной занятости [Срничек, 2018; Шевчук, 2020], включающий услуги логистики и доставки, такси, а многие сервисы (от репетиторства до психотерапии) ушли в режим онлайн. Что касается платформенной занятости, то, конечно, в первую очередь она возросла за счет прекарных, относительно низкооплачиваемых занятий неквалифицированного "простого" труда - велокурьеров и таксистов, жестко привязанных к своим онлайн-платформам - "Яндекс", "Самокат", Ozon, Delivery club и др. О профессионализации здесь можно говорить 
не в том традиционном смысле, как это обычно понимают социологи профессий (формирование корпуса специального знания, автономия, защита юрисдикции, повышение статуса в сфере труда, этические принципы и т. п.), а скорее как об антропологическом феномене вырабатывания схожих практик, тактик и уловок на рабочем месте, направленных как на то, чтобы лучше выполнять свою работу, так и на избежание менеджериального цифровизированного контроля и на адаптацию к работе в условиях мегаполиса с его подчас агрессивной средой.

При этом институт профессий остается, пожалуй, одним из ключевых индикаторов глобальных общественных трансформаций, наметившихся в последние годы и только ускорившихся под влиянием пандемии. Развитие и укоренение неолиберальной капиталистической модели, беспрецедентная цифровизация разных сторон социального взаимодействия, политические, экономические и экологические кризисы самого разного порядка и масштаба - все это не могло не сказаться на сфере труда и занятости и не могло не оказать заметного влияния на изменение роли профессионалов в современном мире. Сегодня все эти процессы, безусловно, находят отражение в многочисленных исследованиях специалистов из различных областей общественных наук, однако социологам во многом еще только предстоит осмыслить те фундаментальные изменения сферы профессионального труда, свидетелями которых мы стали в последние несколько лет.

Конечно, продолжающаяся пандемия COVID-19 стала мощным катализатором уже наметившихся трендов - от перехода на интернет-технологии в образовании до стремительной экспансии многочисленных онлайн-платформ и серьезного дополнения (а в предельном случае - полной замены) традиционных функций работников соответствующими программными алгоритмами в самом недалеком будущем. Все это порождает серьезные неопределенности, связанные с коррозией сложившихся профессиональных ролей и создает вполне реальную угрозу агентности работников самого разного уровня - от курьеров по доставке еды до университетских профессоров. В условиях же усиления роли государственного аппарата, использующего управленческие практики биополитики [Фуко, 2010], на фоне борьбы с распространением инфекции и принятия в этой связи жестких управленческих решений все эти риски становятся еще более актуальными и требующими серьезного социологического анализа, сфокусированного на том, как данные трансформации переживаются специалистами и какие последствия они могут иметь для будущего профессиональных сообществ.

Мы полагаем, что все эти трансформации сферы занятости и профессиональных институтов, ускорившиеся под влиянием пандемии, требуют серьезного социологического осмысления, которое должно заключаться как в эмпирических исследованиях конкретных профессиональных групп и сообществ, так и в производстве соответствующих теоретических схем, адекватно описывающих и объясняющих происходящие процессы в контексте более широких социетальных изменений. Нет нужды говорить, что важность этой работы обусловлена не в последнюю очередь тем очевидным фактом, что для большинства людей сфера труда и занятости напрямую связана с жизненным благополучием, выражающимся как в достижении материальных целей, так и в самореализации через профессию, а потому едва ли можно считать внимание исследователей к этой теме избыточным. Таким образом, 
мы надеемся, что данный тематический выпуск станет значимым шагом в сторону нового социологического осмысления динамично изменяющейся трудовой и профессиональной реальности.

В следующем разделе охарактеризуем общее состояние современной социологии профессий и, с опорой на последние зарубежные исследования, укажем на важные и актуальные проблемы этого дисциплинарного поля. Далее мы представим краткий обзор статей, составляющих специальный номер. Наконец, в заключении обсудим некоторые перспективные, на наш взгляд, направления дальнейших исследований в области социологии профессий, занятости и труда.

\section{Современная социология профессий: международный контекст}

Только в 2021-2022 гг. ведущие российские и зарубежные журналы станут по-настоящему откликаться публикациями о влиянии пандемии, локдауна и глубоких изменений в экономике на мир профессий и занятий. Многие исследования этого влияния еще продолжаются, а их результаты неочевидны, поскольку все мы находимся в центре этого глобального тайфуна и пока еще неясно, каким будет мир после него. Между тем некоторые сюжеты в исследованиях профессий и профессионализма остаются актуальными уже на протяжении некоторого времени и не теряют практической остроты и теоретической емкости.

Традиционная социология профессий как самостоятельная дисциплинарная область в настоящее время находится в кризисе, поскольку сложившиеся теоретические модели профессионализма проверяются на прочность стремительно меняющейся структурой профессиональной занятости, методами контроля и управления профессиональным трудом и трансформациями содержания этого труда. Поэтому исследователям занятий и профессий все сложнее применять аналитические схемы традиционных англо-американского или континентального подходов к пониманию профессионализма, которые уже не улавливают драматических перемен в мире занятий. Социологи находятся в поисках новых объяснительных моделей профессионализма, и здесь стоит обратить внимание на работы последних лет нидерландского исследователя Мирко Ноордеграафа (Mirko Noordegraaf), профессора Утрехтского университета в области менеджмента. М. Ноордеграаф стремится выработать обновленные теоретические модели профессионализма, учитывающие организационный, технологический и управленческий контексты труда специалистов. В своей недавней статье он развивает идею "связующего профессионализма" (connective professionalism), который отличается от "оградительного профессионализма" (protective professionalism), основанного на принципах автономии, четкого определения юрисдикции профессионального труда, значимой роли ассоциаций и т.д., и от "гибридного профессионализма" (hybrid professionalism), включенного в менеджериальную логику жизни современных организаций [Noordegraaf, 2015]. "Связующий профессионализм" предполагает рассмотрение профессий в измерениях "экспертизы", "автономии" и "авторитета", и во всех трех измерениях главным становится занятие в его перформативности - отношении с клиентами, организационными условиями, объектами профессиональной экспертизы, то есть с процессом, а не со стабильной ситуацией неизменности профессионального статуса, власти и экспертного знания 
[Noordegraaf, 2020]. Ноордеграаф рассматривает "связующий профессионализм" в качестве важной перспективы теоретического анализа профессий и занятий с учетом динамики идентичности и ре-активной включенности профессионалов в различные коммуникативные сети. Концепция "связующего профессионализма" вызвала критику, в которой говорится, что Ноордеграаф недостаточно учитывает внутрипрофессиональное неравенство, власть и агентность профессионалов [Adams et al., 2020].

Французская исследовательница С. Салман пишет о довольно старом феномене профессионализма - "корпоративном профессионализме", ставшем результатом укрупнения управленческих штабов и усложнения организационных структур компаний в 1970-1980-е годы, оказывающих широкий спектр интеллектуальных услуг - от консалтинга до рекламы [Salman, 2019]. Дальнейшей ступенью развития моделей профессионализма, по Салман, становится «клиентский профессионализм" с идеями "сопроизводства" (через более вовлеченные и открытые отношения с клиентами) и "щедрости" (через обмен знаниями с другими профессионалами, в том числе и с конкурентами), попыткой выйти из иерархической клетки крупных организационных единиц. "Клиентский профессионализм" сначала появлялся вне больших компаний и практиковался независимыми профессионалами, но требования рыночной гибкости стимулируют его интеграцию в организацию труда профессионалов, работающих в качестве наемных работников [Salman, 2021].

Последствия интервенций неолиберального эконометрического мышления в пространство труда профессионалов оказываются неожиданными и могут вести к разрушению ряда базовых нормативных принципов профессионализма, одним из которых является коллегиальность. С одной стороны, она позволяла говорить о профессионалах в терминологии сообществ с их моральными требованиями и этическими ограничениями, а с другой - это агентный ответ профессионалов [Denis et al., 2019] на изменения в организационном контексте их труда. Коллегиальность никогда не могла полностью заменить бюрократические правила и принципы, но была практикой “мягкого" руководства в организациях с преобладанием в них профессионалов, подобно университетам и исследовательским центрам. Наступление на принципы коллегиальности началось вместе с распространением идей NPM и неолиберальными реформами профессий (в первую очередь академической и медицинской) и предполагало индивидуализацию карьерных траекторий профессионалов вместе с переходом к квантифицированной оценке их индивидуальных результатов. Авторы большой теоретической статьи о коллегиальности в профессиях говорят о двух формах коллегиальности: "коллегиальности как сопротивлении" бюрократическому и административному давлению, отстаиванию профессиональной автономии и "коллегиальности как сопроизводстве" - форме институциональной адаптации профессий к меняющемуся организационному контексту в отличие от более конфронтационной стратегии сопротивления [ibidem]. Обе формы коллегиальности авторы иллюстрируют примерами из сферы здравоохранения.

В сфере медицины продолжаются процессы трансформации профессионального статуса врачей в ходе длительных и глубоких реформ здравоохранения, одной 
из важных сторон которых становится менеджериализация руководства больницами. Тенденции депрофессионализации и утраты части профессиональной автономии немецкими врачами были подтверждены в ходе недавнего исследования ситуации труда одной из групп медицинских профессионалов - "сменных врачей" (Locum Physicians) [Wilkesmann et al., 2019]. При этом авторы исследования видят новые перспективы репрофессионализации в медицинской сфере, которая может быть основана на выращивании новых форм низовой peer-to-peer солидарности, самоменеджмента и медицинского профессионализма, опирающегося на научное знание, а также стремлении повысить свой финансовый статус, то есть на появлении "гибридного профессионализма" в терминологии Ноордеграафа [Noordegraaf, 2015]. Нидерландские исследователи на материалах интервью и включенного наблюдения за трудом врачей показали, как профессионалы, постоянно работающие с клиентами, используют разные институциональные логики в своей повседневной работе [ten Dam, Waardenburg, 2020]. Авторы выделяют пять дискурсивных логик, используемых врачами в разных обстоятельствах для выполнения своей профессиональной работы:

- медицинская профессиональная экспертная логика;

- менеджериальная логика, связанная с темой контроля и процессами управления;

- коммерческая логика, ориентирующая на предпринимательское видение и маркетинг;

- консультационная логика, укорененная в партнерские отношения внутри сообщества;

- пациенто-ориентированная логика, связанная с сотрудничеством врача и пациента в решении задач лечения и нахождения в системе здравоохранения.

Эти логики институционализированы в виде дискурсивных регистров, на которые переключаются врачи в описаниях своего труда в зависимости от контекста.

Мир современных занятий в области управления и финансов стал активно развиваться вместе с организационным усложнением индустриального и постиндустриального общества, и эти занятия не могли повторять путь профессионализации, который прошли "старые профессии", подобные праву и медицине. Поэтому стратегия профессионализации "новых" занятий строилась на организационном, институциональном и культурном мимезисе уже сложившихся профессий - включая создание системы образования, ассоциаций, притязания на теоретическое осмысление практической работы и т. д. Международная группа исследователей охарактеризовала специфику профессионализации таких новых занятий, которые в основном сконцентрированы в "профессиональных сервисных фирмах" (professional service firms or PSF) и включают широкий спектр деятельностей,управленческий консалтинг, архитектуру, дизайн и другие интеллектуальные услуги [Kipping, Buhlmann, David, 2019]. Эти занятия стремятся формировать "имидж" профессии, воспроизводя основные элементы институционального декора профессионализма, но в основном они формируются в организационной среде «мягких бюрократий" и их труд опирается на менеджериалистские принципы, а поэтому их путь профессионализации несколько иной, чем был у “старых" профессий: он связан с карьерными возможностями, репутацией и позицией их организации, 
а также с конвертацией различных типов капитала в сфере своей специализации. Сюжет новых форм профессионализма, которые являются спорными территориями социологии профессий, развивается на примере изучения итальянских консультантов по управлению [Maestripieri, 2019].

Тема проблематизации профессионального труда в организационном контексте продолжена в исследовании австралийских авторов, которые анализируют дискурсивные тактики реагирования специалистов юридических фирм по работе с правами интеллектуальной собственности (intellectual property (IP) law firm) на организационные изменения [Heizmann, Mastio, Ahuja, 2020]. Авторы пишут об "отрицании" - несогласии с изменениями; "регрессии" - отсылках к традиционным ценностям профессионализма, таким как автономия; “проекции" - отсылках к особенностям личных и деловых качеств ("отсутствие деловой хватки"), препятствующих принятию коммерциализированной ориентации реформ в организации. В исследовании говорится, что рыночная логика и неоменеджериальные техники контроля являются главными катализаторами острой реакции профессионалов на организационные изменения.

Практически все экономисты и социологи труда и занятости говорят о сильнейшем влиянии технологических новаций на профессиональную структуру и содержание труда. Стали появляться устойчивые термины «профессии-пенсионеры», "умирающие профессии" и "профессии будущего", обозначающие стремительную динамику сферы занятости под воздействием очередной промышленной революции и цифровизации труда. Британский исследователь Стен Лестер в небольшом эссе рассуждает о воздействии новых технологий на профессиональную работу [Lester, 2020]. По мнению автора, новые технологии могут улучшать и расширять возможности для профессионального труда, приводить к автоматизации трудовых задач, устраняя или минимизируя участие человека и, наконец, новые технологии ведут к отмиранию целых групп занятий, как это произошло в свое время с машинистками и телефонистками. При этом алгоритмизация и дисперсиализация контроля над трудом профессионалов угрожает их автономии, а сама идея неотчуждаемого профессионализма, опирающегося на симбиоз личного опыта, интуиции и профессиональных знаний, ставится под сомнение, поскольку источником решений, принятых профессионалом, в конечном счете оказывается его личность — «черный ящик" для внешнего контроля.

Цифровизация касается разных сторон жизни и труда, в том числе деятельности профессионалов, что показал переход на дистанционный режим работы в период пандемии 2020-2021 гг. Между тем инновационные формы оказания профессиональных услуг с использованием цифровых технологий активно развиваются уже на протяжении некоторого времени: например, в России для снижения географического неравенства в предоставлении медицинской помощи стали применять телемедицину, и для этого в 2017 г. даже был принят специальный законодательный акт ${ }^{1}$, регламентирующий применение дистанционных технологий в здравоохранении. В период пандемии телемедицина стала еще актуальнее, поскольку именно больницы и поликлиники нередко провоцировали вспышки

\footnotetext{
1 Федеральный закон от 29 июля 2017 г. N 242-Ф3 «0 внесении изменений в отдельные законодательные акты Российской Федерации по вопросам применения информационных технологий в сфере охраны здоровья".
} 
коронавируса на начальном этапе эпидемии. В других странах популярность телемедицины также растет, и датская исследовательница К. Вестергаард исследовала, как она влияет на профессиональные сообщества и профессионализм медиков. Используя метод этнографии и понятие практик Е. Шацкого, К. Вестергаард показала, как трансформируется работа физиотерапевтов и медицинских сестер. Автор констатировала изменения в профессионализме медиков, включенных в телемедицину, в перспективе пересборки применения специальных знаний и аффективной перформативности труда, особенно ярко проявленной в работе физиотерапевтов [Vestergaard, 2021].

Продолжает интересовать исследователей выстраивание профессиональных идеологий через риторические приемы легитимации позиции в сфере занятости, что особенно важно для сфер деятельности, которые время от времени становятся объектом общественной критики, как это произошло с банковским сектором в период кризиса 2008 г., одной из причин которого стали деструктивные действия ряда крупных финансовых институтов. Группа британских исследователей опросила представителей менеджмента ведущих банков с целью выявления нарративных способов легитимации профессиональной роли в ситуации общественного подозрения в адрес финансистов, чьи ошибки и нарушения этики способствовали финансовому кризису 2008 г. [Siebert, Martin, Simpson, 2020]. В работе говорится о формах моральных оправданий и техник риторической нейтрализации, к которым прибегают представители банковского сектора, о риторических приемах избегания ответственности и трансфера собственной роли в позицию не виновника, но жертвы.

Зарубежных коллег продолжают волновать "вечные темы" социологии занятий и профессий - циркуляции и согласованности профессионального знания в системе специального образования [Hermansen, 2020], гендерного неравенства в профессиях - в частности, в академической сфере [Gaiaschi, 2021], влияние менеджериализма на профессиональную культуру street-level бюрократов (streetlevel bureaucrats (SLBs)) социальной сферы [Jacobsson, Wallinder, Seeing, 2020], включая эффект "волокиты" ("red tape»), вызванный излишней стандартизацией и частыми изменениями в управленческих процедурах [Dudau, Kominis, Brunetto, 2020]. Появились и работы, посвященные трансформации женских профессиональных карьер в период внешних потрясений [Cohen, Duberley, 2020].

\section{Социология профессий, труда и занятости: обзор номера}

Подобная же тематическая палитра, включающая как традиционные исследовательские вопросы, так и актуальные изменения в сфере профессий и занятий, находит свое отражение в работах отечественных социологов. Статьи, представленные в номере, охватывают большое число разнообразных проблем, так или иначе соотносящихся с теми трансформациями, которые сфера профессий, труда и занятости претерпела (и продолжает претерпевать) за последние годы. В фокусе авторов, представляющих различные концептуальные и методические традиции, находятся как общие тренды и закономерности процессов трансформации современных профессиональных институтов, так и специфические характеристики конкретных профессиональных групп, многие из которых для нашего 
общества относительно новы. С учетом подобного разнообразия мы приняли решение (во многом - со значительной долей условности) разделить статьи номера на несколько тематических рубрик, отражающих определенное различие в круге проблем, с которыми имеют дело авторы. Далее очень кратко охарактеризуем вклад каждой из работ.

\section{Социология профессий}

В работе И. Козиной и Е. Серёжкиной «Оценка психосоциальных рисков и качество трудовой жизни российских профессионалов" представлены ключевые характеристики общего "допандемийного" состояния российских профессионалов различных специальностей с учетом базовых составляющих трудового и профессионального благополучия, а также основных рисков, какими они виделись работникам буквально за полтора года до глобального наступления новой коронавирусной инфекции.

Другие авторы изучают специфику конкретных профессиональных групп, зачастую пытаясь отразить и те изменения, которые произошли в деятельности профессионалов под влиянием пандемии. В частности, К. Галкин в статье “„Как в тайге или глубоком космосе“: тематический анализ смыслов работы и повседневности молодых сельских врачей в период пандемии COVID-19" рассматривает взгляды молодых сельских врачей на повседневность своего труда в период распространения коронавируса. Автор акцентирует внимание на способах осмысления профессионалами своей деятельности в новой реальности, которая, с их точки зрения, только усилила наметившиеся негативные процессы, связанные с потерей коллегиальности, экспертности и авторитета в глазах пациентов.

Сразу две работы обращаются к проблематике гендера в инженерных профессиях: И. Антощук представляет общий обзор многочисленных исследований, так или иначе рассматривающих профессиональные роли и карьерные траектории женщин-инженеров в российском контексте. Н. Руденко и Р. Малюшкин, основываясь на открытых данных социальной сети, анализируют гендерные особенности трудовой миграции и профессионально-образовательных траекторий представителей инженерных специальностей.

В исследовании К. Поповой “Стандартизация и профессионализм в работе операторов колл-центра", выполненном в традиции этнометодологии, показана специфика работы операторов колл-центров через призму соотношения, с одной стороны, формализованной и унифицированной логики производства ответов на вопросы, а с другой - необходимости поиска уникальных решений и работы со специфическими трудностями и запросами клиентов.

Двумя статьями представлена актуальная проблема трансформации труда преподавателей под влиянием пандемии коронавируса в контексте общего современного кризиса академической профессии. Так, Р. Абрамов, И. Груздев, У. Захарова и Е. Терентьев на основе проведенного исследования отмечают амбивалентность эффекта массового перехода на дистанционные образовательные технологии, связанную как с возросшей активной ролью преподавателей в организации обучения и приобретением новых компетенций, так и с усилением административного контроля и опасениями полной потери профессионального статуса из-за 
тотальной цифровизации. Ж. Чернова и Л. Шпаковская раскрывают специфику преподавательской деятельности через обращение к понятию эмоционального труда, демонстрируя сложности, с которыми преподаватели столкнулись при переходе на онлайн-взаимодействие со студентами.

Помимо исследований традиционных профессиональных групп - врачей, инженеров, преподавателей - авторы номера обращаются и к относительно новым трендам в области развития профессиональных сообществ и институтов. Так, Э. Ариф и Т. Кузьминова анализируют взгляды молодых проэкологически настроенных предпринимателей и раскрывают специфику их этических представлений, основанных на критическом отношении к идеологии неограниченного потребления. Кроме того, сразу две работы посвящены изучению возникновения новых немедицинских практик родовспоможения и институционализации профессии доулы: А. Ожиганова комплексно анализирует ключевые признаки профессионализации доул в России, в то время как Т. Кукса стремится раскрыть особенности коммуникативных практик и внешнего позиционирования доульского сообщества, отражающие его стремление к легитимации в глазах как медицины, так и потенциальных клиенток и широкой общественности.

\section{Социология труда и занятости}

В статье К. Ерицян, М. Русаковой, А. Александровой и Н. Усачевой на материалах опроса жителей Санкт-Петербурга демонстрируются ключевые изменения уровня трудовой занятости представителей разных профессиональных групп, произошедшие после введения в городе режима самоизоляции, а также анализируется их влияние на психологическое благополучие. Ю. Андреева и Е. Лукьянова в работе “Стратегии занятости рабочих в период пандемии COVID-19" обращаются к поведению рабочих Ульяновской области в период пандемии. Авторы отмечают относительную стабильность стратегий занятости рабочих, которая во многом обусловлена необходимостью физического присутствия на рабочих местах даже в период действия карантинных мер.

Исследование К. Попковой и Е. Балабановой «Мотивация труда творческих работников: нормативные представления и реальность трудовой жизни" демонстрирует серьезное противоречие между декларируемым в неформализованных интервью приоритетом содержательных аспектов работы и выраженностью утилитарных установок, проявившихся на уровне количественного опроса. Е. Андреева и Ю. Карачурина в своей работе выделяют ключевые стратегии миграции российских врачей в сельскую глубинку, соотносящиеся с различными типами мотиваций и целями, которые преследуют специалисты, решившие переехать на периферию.

Кроме того, все большее внимание исследователей привлекают различные аспекты цифровизации труда и риски, которые она несет с точки зрения значительного ослабления агентности профессионалов. Так, А. Тюлюпо в статье "Факторы (не)доверия заказчикам на биржах удаленной работы" на основе данных "цифровых следов" анализирует факторы недоверия заказчикам со стороны фрилансеров, работающих на биржах удаленной работы. Автор также проясняет ключевые индикаторы, которые потенциальные работники используют при принятии решений о взаимодействии с работодателями. А. Шевчук, Д. Чижова, 
Д. Демина и В. Чугункова исследуют особенности труда таксистов в условиях небывалого распространения цифровых платформ, раскрывая отношение водителей к использованию компьютерных алгоритмов как средства организации их труда.

Статья К. Таракановской “Материнство и университет: стратегии баланса жизни и работы" посвящена проблеме баланса жизни и труда среди представительниц академической профессии. Автор раскрывает многообразие способов конституирования отношения к этой проблеме и выработки соответствующих поведенческих стратегий, которые демонстрируют сотрудницы университетов.

\section{Государство и общество}

Н. Большаков, Д. Присяжнюк и Е. Ярская-Смирнова рассматривают ключевые свойства и дилеммы нового социального менеджмента, раскрывая противоречия между фокусом на "эффективности", характерным для неолиберальной менеджериальной идеологемы, и гуманной ориентацией на потребности социально незащищенных групп населения.

Две статьи номера посвящены проблематике морально-этических взглядов отечественных юристов. А. Казун обращается к анализу публичности как стратегии юридической защиты, раскрывая мотивацию адвокатов для привлечения внимания СМИ и создания общественного резонанса вокруг уголовных дел. С. Ушкин и Е. Коваль, в свою очередь, рассматривают различные представления о справедливости будущих российских юристов в связи с их ценностно-нормативными установками относительно ряда социально значимых проблем.

Наконец, в статье М. Певной, А. Кульминской, Е. Широковой и Е. Шуклиной представлено исследование практик волонтерства среди молодежи Свердловской области, демонстрирующее определенную специфику, которую эта деятельность приняла в период пандемии.

\section{Перспективы дальнейших исследований}

Многие статьи нашего номера опираются на исследования, которые были сделаны накануне или в самом начале пандемических трансформаций, а поэтому сегодня могут читаться как исторические очерки. Это особенность академической работы и публикационного цикла в научных журналах, который имеет собственную темпоральность. Однако потеряли ли тексты актуальность? На наш взгляд, нет - по нескольким причинам.

Во-первых, состояние некоторых сфер занятости зафиксировано перед началом необратимых изменений, вызванных реакцией общества и экономики на пандемию, а поэтому могут рассматриваться как исторические точки отсчета при анализе динамики профессионализма в этих областях.

Во-вторых, мы видим, что Россия и другие страны лавируют между пандемийными ограничениями и их снятием, исходя из эпидемиологической ситуации, что позволяет говорить о стремлении найти шаткий эквилибриум “новой нормальности" в том числе и в мире профессионального труда. Это означает, что напряжения карантинного периода сменяются периодами "старой нормальности", в институциональном и практическом смыслах занятия и профессии все еще ностальгически озабочены возвращением к обычному порядку существования, а следовательно, 
представленные тексты вполне укладываются и в текущую ситуацию в различных формах занятости.

При этом возникает вопрос о том, каковы дальнейшие направления исследований занятий и профессий на российском материале. Конечно, еще долгое время будут актуальны сюжеты, связанные с влиянием пандемической и постпандемической ситуации на отдельные занятия и профессии - от медицины до туризма и образования. Наряду с этим, как нам кажется, стоит обратить внимание на долгосрочные последствия карантина и изменений условий труда для различных сторон профессионализма, включая общественный образ профессии, расширение или сужение пространства профессиональной власти и экспертизы, степени увеличения и уменьшения автономии, новые вызовы профессиональной этике, а также место сообщества и профессиональных культур в адаптации к меняющейся окружающей реальности.

Очевидно, пандемия форсировала цифровизацию отдельных секторов занятости, в первую очередь связанных с доставкой и перевозками, а также с рядом интеллектуальных услуг, однако цифровые платформы и процессы замещения организационного профессионализма фрилансерским наблюдались и до этого [Стребков и др., 2016]. Поэтому роль технологических новаций в преобразовании профессионализма еще долго будет важным объектом изучения социологами, поскольку технологии могут способствовать появлению и профессионализации одних занятий и вести к статусному упадку других. В действительности за лейблом "цифровизация" скрывается множество различных сюжетов, включая замещение "живых работников" искусственным интеллектом, автоматизированные системы наблюдения и контроля над профессионалами, возникновение новых профессионализованных занятий, подобных data science, претендующих на гегемонические позиции не только в сборе и обработке больших данных, но и на объяснение и теоретические генерализации относительно социального поведения. Все это заслуживает внимания исследователей.

Социология профессий, в отличие от социологии труда и занятости, преимущественно сосредотачивалась на изучении занятий нефизическим трудом, требующих специального образования и обладающих претензиями на автономию и статус городского образованного среднего класса. Между тем в России для исследователей имеются большие "теневые зоны", которые касаются профессиональной культуры, статуса и трудовых практик "нового пролетариата" - работников служб ЖКХ крупных городов, в основном этнических мигрантов, инженерно-технического персонала российских ресурсодобывающих частных и государственных компаний, который трудится в труднодоступных регионах преимущественно вахтовым методом. Барьеры для входа в поле при изучении данных трудовых сфер нередко являются критическими для реализации полевого этапа исследования, однако изучение этих групп занятий чрезвычайно важно для понимания природы российского капитализма в контексте теорий модернизации и колониализма, поскольку именно эти области занятости служат лакмусовой бумажкой глубинных трансформаций и других профессий. Безусловно, стоит обратить внимание на политические и ценностные вызовы, с которыми столкнулись профессии в России и в мире. Российская ситуация усугубляется планомерным наступлением государства 
на профессиональную автономию в сфере права, журналистики, академической работы, секторе НКО и др., что вызывает беспокойство, так как может негативно сказаться на качестве профессиональной экспертизы, циркуляции профессионального знания и исполнении профессионального долга. Здесь важно обращение к непростой истории профессионализма в Российской империи и СССР. При этом российские профессии являются частью глобального профессионального мира с его трендами и моральными дилеммами, вызванными распространением cancel culture, предъявляющей новые требования к практике работы специалистов и формирующей новые критерии ее оценки в категориях морали и этики. Россия только начинает путь в этом направлении, но уже есть очевидное влияние этого морального течения на сферу искусства и образования.

\section{Список литературы (References)}

Срничек Н. Капитализм платформ. М. : Издательский дом ВШЭ, 2018.

Srnichek N. (2018) Platform Capitalism. Moscow: HSE Publishing House. (In Russ.)

Стребков Д.О., Шевчук А. В., Спирина М.О. Самостоятельная занятость на рынке удаленной работы: распространение инновационной трудовой практики // Мониторинг общественного мнения: Экономические и социальные перемены. 2016. № 6. С. 89-106.

Strebkov D. O., Shevchuk A. V., Spirina M. O. (2016) Self-employment in the Remote Work Market: Diffusion of Innovative Labor Practice. Monitoring of Public Opinion: Economic and Social Changes. No 6. P. 89-106. (In Russ.)

Фуко М. Рождение биополитики. СПб.: Наука, 2010.

Foucault M. (2010) Naissance de la Biopolitique. Saint Petersburg: Nauka. (In Russ.)

Шевчук А. В. От фабрики к платформе: автономия и контроль в цифровой экономике // Социология власти. 2020. Т. 32. № 1. С. 30-54. https://doi.org/ 10.22394/2074-0492-2020-1-30-54.

Shevchuk A.V. (2020) From Factory to the Platform: Autonomy and Control in the Digital Economy. Sociology of Power. Vol. 32. No. 1. P. 30-54. https:// doi.org/10.22394/2074-0492-2020-1-30-54. (In Russ.)

Adams T. L., Kirkpatrick I., Tolbert P. S., Waring J. (2020) From Protective to Connective Professionalism: Quo Vadis Professional Exclusivity? Journal of Professions and Organization. Vol. 7. No. 2. P. 234-245. https://doi.org/10.1093/jpo/joaa014

Cohen L., Duberley J. (2020) Women in Extraordinary Times: The Impact of External Jolts on Professional Women's Careers. Journal of Professions and Organization. Vol. 7. No. 3. P. 247-264. https://doi.org/10.1093/jpo/joaa019.

Denis J.-L., Veronesi G., Régis C., Germain S. (2019 Collegiality as Political Work: Professions in Today's World of Organizations. Journal of Professions and Organization. Vol. 6. No. 3. P. 323-341. https://doi.org/10.1093/jpo/joz016. 
Dingwall R., King M. D. (1995) Herbert Spencer and the Professions: Occupational Ecology Reconsidered. Sociological Theory. Vol. 13. No. 1. P. 14-24. https:// doi.org/10.2307/202002.

Dudau A., Kominis G., Brunetto Y. (2020) Red Tape and Psychological Capital: A Counterbalancing Act for Professionals in Street-Level Bureaucracies. Journal of Professions and Organization. Vol. 7. No. 3. P. 334-350. https://doi.org/10.1093/ jpo/joaa024.

Gaiaschi C. (2021) The Academic Profession in Neoliberal Times: A Gendered View. Professions and Professionalism. Vol. 11. No. 1. https://doi.org/10.7577/pp.3901.

Heizmann H., Mastio E., Ahuja S. (2020) Stuck in Defensive Professionalism: Undermining Organizational Change in an Intellectual Property Law Firm. Journal of Professions and Organization. Vol. 7. No. 2. P. 117-133. https://doi.org/10.1093/jpo/joaa009.

Hermansen H. (2020) Knowledge Discourses and Coherence in Professional Education. Professions and Professionalism. Vol. 10. No. 3. e3713. https://doi.org/10.7577/ pp.3713

Jacobsson K., Wallinder Y., Seing I. (2020) Street-Level Bureaucrats Under New Managerialism: A Comparative Study of Agency Cultures and Caseworker Role Identities in Two Welfare State Bureaucracies. Journal of Professions and Organization. Vol. 7. No. 3. P. 316-333. https://doi.org/10.1093/jpo/joaa015.

Kipping M., Buhlmann F., David T. (2019) Professionalization Through Symbolic and Social Capital: Evidence From the Careers of Elite Consultants. Journal of Professions and Organization. Vol. 6. P. 265-285. No. 3. https://doi.org/10.1093/jpo/joz014.

Lester S. (2020) New Technology and Professional Work. Professions and Professionalism. Vol. 10. No. 1. e3836. https://doi.org/10.7577/pp.3836.

Maestripieri L. (2019) Fragmented Fields: Professionalisms and Work Settings in Italian Management Consultancy. Journal of Professions and Organization. Vol. 6. No. 3. P. 357-376. https://doi.org/10.1093/jpo/joz011.

Noordegraaf M. (2015) Hybrid Professionalism and Beyond. Journal of Professions and Organization. Vol. 2. No. 2. P. 198-206.

Noordegraaf M. (2020) Protective or Connective Professionalism? How Connected Professionals Can (Still) Act as Autonomous and Authoritative Experts. Journal of Professions and Organization. Vol. 7. No. 2. P. 205-223. https://doi.org/10.1093/ jpo/joaa011.

Rogozin D., Vyugovskaya E. (2021) Teachers' Perceptions of Distance Learning amid the COVID-19 Pandemic in Russia. Higher Education in Russia and Beyond. Vol. 2. P. $6-7$.

Salman S. (2019) Towards a 'Client Professionalization' Process? The Case of the Institutionalization of Executive Coaching in France. Journal of Professions and Organization. Vol. 6. No. 3. P. 286-303. https://doi.org/10.1093/jpo/joz012. 
Salman S. (2021) Client Professionalization, a Resource for Heterogeneous Professionals: For a Pluralistic Account of Corporate Professions. Professions and Professionalism. Vol. 11. No. 1. https://doi.org/10.7577/pp.3904.

Siebert S., Martin G., Simpson G. (2020) Rhetorical Strategies of Legitimation in the Professional Field of Banking. Journal of Professions and Organization. Vol. 7. No. 2. P. 134-155. https://doi.org/10.1093/jpo/joaa010.

ten Dam E. M., Waardenburg M. (2020) Logic Fluidity: How Frontline Professionals Use Institutional Logics in Their Day-to-Day Work. Journal of Professions and Organization. Vol. 7. No. 2. P. 188-204. https://doi.org/10.1093/jpo/joaa012.

Tomczyk L. (2021) E-Learning in Poland: Challenges, Opportunities and Prospects for Remote Learning during the COVID-19 Pandemic. Higher Education in Russia and Beyond. Vol. 2. P. 10-12.

Vestergaard K. (2021) Changes in Professionalism Through the Practice of Telemedicine: Conceptualizing a Situated Sense Filter. Professions and Professionalism. Vol. 11. No. 2. e3857. https://doi.org/10.7577/pp.3857.

Wilkesmann M., Ruiner C., Apitzsch B., Salloch S. (2019) "I Want to Break Free": German Locum Physicians Between Managerialism and Professionalism. Professions and Professionalism. Vol. 10. No. 1. e3124. https://doi.org/10.7577/pp.3124. 